\title{
Effects of combined progesterone and $17 \beta$-estradiol treatment on the transcriptome of cultured human myometrial smooth muscle cells
}

\author{
Sreenath Chandran,* Michael T. Cairns,* Margaret O'Brien, Enda O'Connell, Kaveh Mashayekhi, \\ and Terry J. Smith \\ National Centre for Biomedical Engineering Science, National University of Ireland Galway, Galway, Ireland
}

Submitted 3 March 2015; accepted in final form 23 October 2015

\begin{abstract}
Chandran S, Cairns MT, O'Brien M, O'Connell E, Mashayekhi K, Smith TJ. Effects of combined progesterone and $17 \beta$-estradiol treatment on the transcriptome of cultured human myometrial smooth muscle cells. Physiol Genomics 48: 50-61, 2016. First published November 3, 2015; doi:10.1152/physiolgenomics.00021.2015.-A transcriptomic analysis of cultured human uterine smooth muscle cells (hUtSMCs) was performed to examine gene expression profiles in smooth muscle in an environment containing the two major steroid hormones that regulate the human myometrium in physiological states associated with estrous, pregnancy, labor, and pathophysiological states such as leiomyoma and endometrial cancer. hUtSMCs were treated with progesterone (P4) and 17 $\beta$-estradiol (E2) individually and in combination, in the presence and absence of RU486 (mifepristone). Transcription of many genes was modulated in the presence of P4 or E2 alone, but almost six times more genes were transcriptionally modulated in the presence of the P4/E2 hormone combination. In total 796 annotated genes were significantly differentially expressed in the presence of both P4 and E2 relative to their expression in untreated cells. Functional withdrawal of P4 by addition of RU486 effectively reversed almost all transcriptional changes caused by P4/E2 treatment. Gene ontology analysis of differentially expressed genes revealed a strong association between P4/E2 treatment and downregulated expression of genes involved in cell communication, signal transduction, channel activity, inflammatory response, and differentiation. Upregulated processes included cell survival, gene transcription, steroid hormone biosynthesis, muscle development, insulin receptor signaling, and cell growth.
\end{abstract}

progesterone; $17 \beta$-estradiol; uterine smooth muscle cells; microarray; transcriptomics

THE TWO STEROID HORMONES, estrogen and progesterone (P4), play vital roles in maintaining pregnancy and initiating labor (51) and more generally in myometrial physiology and contractility. P4 maintains uterine quiescence during pregnancy, while estrogen induces uterine contraction at labor (49-51). These hormones fluctuate relative to each other throughout life from puberty, through the fertile years, to the postfertile years and also within these life stages during specific physiological states such as estrous, pregnancy, labor, and menopause. Furthermore, both hormones have profound effects on pathophysiological conditions such as leiomyoma, endometriosis, and endometrial cancer.

In maternal physiology these hormones induce changes that prepare the mother for pregnancy and aid in conceptus development (11). In most species, a sharp decline in circulating P4 and an increase in estrogen are observed toward parturition $(11,38)$. However, in humans, no marked difference in the levels of circulating $\mathrm{P} 4$ or estrogen is noted before or at term

* S. Chandran and M. T. Cairns contributed equally to this study.

Address for reprint requests and other correspondence: T. J. Smith, NUI Galway, Galway, Republic of Ireland (e-mail: Terry.Smith@nuigalway.ie).
(51). Hence, in humans, withdrawal of $\mathrm{P} 4$ and responsiveness of the myometrium to circulating estrogen during labor is believed to occur at a functional level, with changes in hormone receptors playing a more important role than the circulating levels of the hormones themselves (50). Understanding the molecular mechanisms underlying the transition of the uterus from a relatively quiescent organ to an actively contracting organ is of utmost importance in predicting and treating disorders of pregnancy, including preterm labor.

Several functional genomics studies have been carried out across a range of species, including humans, to understand the molecular changes underlying the transition of the quiescent uterus to a rhythmic and actively contracting organ during parturition $(1,5,8,12,13,16,17,26,31,53,56,60)$. In their analysis of all published microarray-based transcriptomic analyses of laboring and nonlaboring myometrium, BreuillerFouche and colleagues (10) identified little overlap between results from different studies. However, each study has identified key molecular regulators and pathways that have broadened our understanding of the complex mechanisms underlying myometrial quiescence and activation. Differences in the cascade of events that precedes human labor, compared with well-studied animal models, makes extrapolation of conclusions from model organisms to humans difficult. The stringency in ethical regulations and difficulty in obtaining patient samples understandably make human studies challenging. Therefore, developing a model cell culture system to study biological events associated with progesterone and estrogen is both relevant and important.

The human myometrium is composed of two distinct smooth muscle layers with a surface epithelium and a supporting capillary network and stromal cells. Clearly a smooth muscle cell culture system cannot model all the intricate interactions within the native myometrium in vivo, nor can it replicate the complex cell signaling and hormonal interactions, as well as other physiological and pharmacological changes that occur in the human myometrium in pregnancy and at the onset of labor. Isolated in vitro cell culture systems, while not mimicking the pregnant laboring human myometrium, can, however, yield important clues as to the roles played by the smooth muscle cells, roles that can be obscured in whole tissue studies. As a result, studies of this nature can also provide important clues as to the overall myometrial system, which can inform the complex physiological events occurring in vivo in pregnant myometrium at the onset of labor.

No transcriptomic study has yet been carried out to investigate the combined effects of $17 \beta$-estradiol (E2) and P4, and the impact of the progesterone inhibitor (RU486) on cultured uterine smooth muscle cells in relation to myometrial contractility, though an in vitro study has recently been published on 
the gene expression profile of immortalized human myometrial cells primarily in response to P4 (69). Global transcriptomic profiling of cultured human uterine smooth muscle cells (hUtSMCs) following combined P4 and E2 steroid hormone treatments, including combined hormone treatment in the presence of the P4 antagonist RU486 to functionally withdraw P4 as occurs at human labor, is presented here.

\section{MATERIALS AND METHODS}

Cell culture and treatment. The primary hUtSMCs used were obtained from Lonza (CLONETICS Uterine Smooth Muscle Cell Systems, CC-2562) and are identical to the Cambrex product described in other published studies $(20,70)$. It has previously been shown that E2 treatment of these hUtSMC cells produces effects expected of steroid hormones on myometrial cells; for example, both mRNA and protein expression of previously reported E2-responsive genes CD38 (23) and GJA1 (also known as connexin CX43) (22) responded as expected to E2 treatment (14). As a control for the Lonza CLONETICS cells, normal primary smooth muscle myometrial cells were isolated from a pregnant nonlaboring patient, with ethical approval having been obtained through the University College Hospital Galway ethics committee, and informed consent obtained from donors.

hUtSMCs were cultured in complete Dulbecco's modified essential medium (DMEM), supplemented with 10\% (vol/vol) fetal bovine serum (FBS) until 50\% confluent. Cells were preconditioned overnight with phenol red-free DMEM (PRF-DMEM), supplemented with $10 \%$ (vol/vol) double charcoal stripped fetal bovine serum (CS-FBS) (Biosera). Cells were subsequently starved of endogenous steroids by incubation in PRF-DMEM supplemented with $2 \%$ (vol/vol) CS-FBS, henceforth referred to as control media, until the cells were $80 \%$ confluent. The time schedule for additions to the hUtSMCs is outlined in Fig. 1.

In brief, at $100 \%$ confluence the following additions were made to flasks 1-6: flask 1 no addition, flask 210 nM E2 (Sigma Aldrich), flasks 3 and $6100 \mathrm{nM} \mathrm{P4} \mathrm{(Sigma} \mathrm{Aldrich),} \mathrm{and} \mathrm{flasks} 4$ and 5 P4 + E2 (P4/E2 samples). Forty-eight hours after these additions, flasks 5 and 6 were supplemented with $1 \mu \mathrm{M}$ RU486 (Sigma Aldrich). Flasks 4 and 5 had been primed at $80 \%$ confluence by supplementation with $100 \mathrm{nM} \mathrm{P4}$. All samples were harvested $72 \mathrm{~h}$ after hormonal treatments at $100 \%$ confluence. Each single experiment consisted of all six treatments, and each experiment was repeated three times on different occasions (18 samples).

Final concentrations of E2 (14), P4, and RU486 were determined empirically. For this study, the optimal level of $\mathrm{P} 4$ addition was determined by real-time RT-PCR quantification of the BCL2 gene, a known P4-responsive gene $(48,72)$, over the range $10-500 \mathrm{nM}$ P4 (data not shown). Induced expression did not increase substantially above $100 \mathrm{nM} \mathrm{P4}$. Again following the gene expression level of BCL2, it was shown that $1 \mu \mathrm{M}$ RU486 significantly inhibited the effects of $100 \mathrm{nM} \mathrm{P} 4$. These concentrations are in line with similar studies $(41,47,72)$.

$R N A$ isolation and quantitative RT-PCR. RNA was isolated using the RNeasy Mini Kit following the manufacturer's protocol (Qiagen). RNA was quantified using the NanoDrop 1000 (Thermo Scientific) and the quality checked using a Bioanalyzer 2100 (Agilent Technologies). Polymerase chain reaction (PCR) was performed using the GoTaq DNA Polymerase Kit (Promega) according to the manufacturer's protocol. The list of genes and corresponding primers sequences obtained from PrimerDepot (19) (http://primerdepot.nci.nih.gov/) is provided in Table 1. Reverse transcription (RT) was carried out using 20 U Superscript II Reverse Transcriptase (Invitrogen) with $2 \mu \mathrm{g}$ RNA and 50 pmol Oligo dT. Real-time RT-PCR was carried out using the QuantiTect SYBR Green PCR Kit (Qiagen) and QuantiTect primers for BCL2 (QT00025011), $\alpha$-tocopherol transfer protein (TTPA) (QT00012040), and elastin microfibril interface-located protein 2 (EMILIN2) (QT00092246) and subjected to 40 cycles of amplification in an ABI StepOnePlus Real-Time PCR System (Applied Biosystems). All gene quantities were normalized to the housekeeping gene (GAPDH). Relative expression was evaluated by the $\Delta \Delta \mathrm{Ct}$ method.

Microarray hybridization and data analysis. Isolated RNA was amplified using the Amino Allyl MessageAmp II aRNA Amplification Kit (Ambion) following the manufacturer's protocol. cDNA was hybridized against the Operon Human Genome Array-Ready Oligo Set Microarrays (version 4.0). The slides contained 35,035 oligonucleotide probes representing $\sim 25,100$ unique genes and 39,600 transcripts, excluding control oligos. All hybridizations were carried out using the OpArray (Operon) hybridization and wash solutions as recommended by the manufacturer. Slides were scanned at $543 \mathrm{~nm}$ (Cy3) with a ScanArray Express HT scanner (Perkin Elmer) and quantified using GenePix 6.0 software (Axon Instruments). For this particular dataset all slides were scanned three times successively and

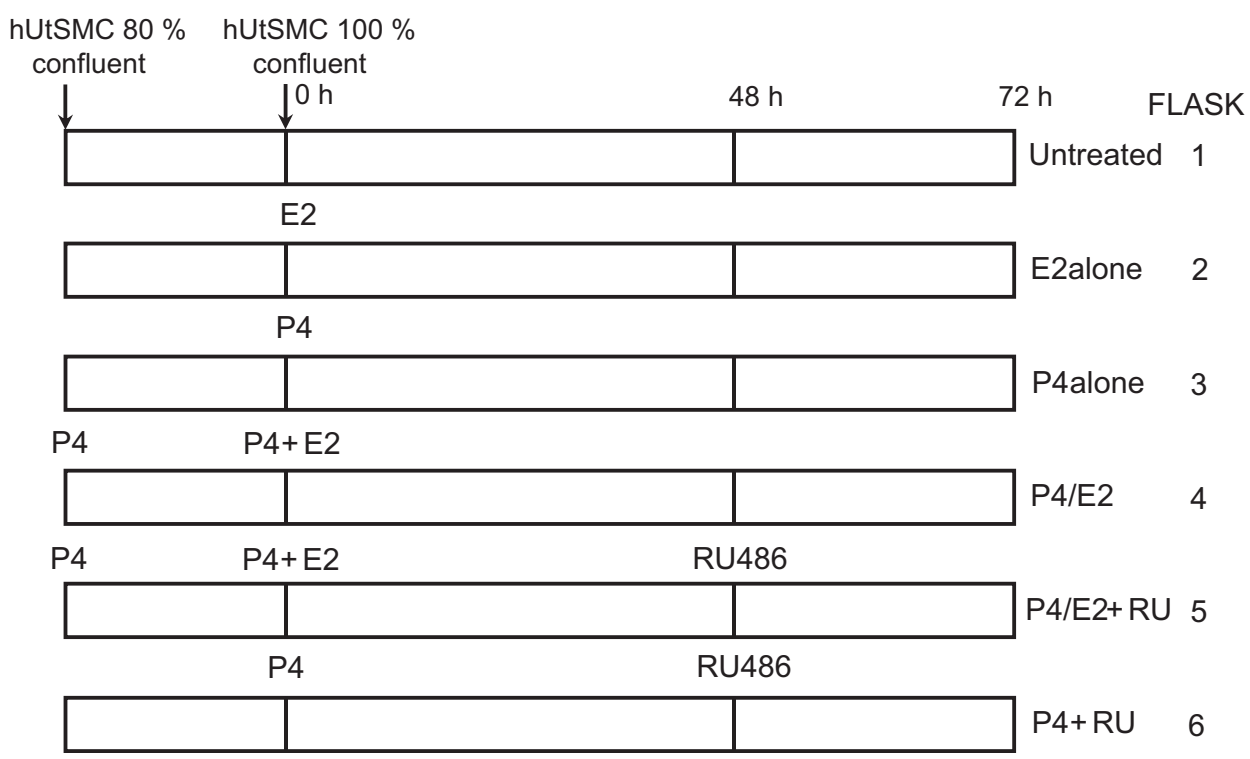

Fig. 1. Experimental strategy for hormone additions to human uterine smooth muscle cells (hUtSMCs). Cells starved of endogenous steroids (see MATERIALS AND METHODS) were grown to $100 \%$ confluence $(t=0 \mathrm{~h})$ and treated with $10 \mathrm{nM} 17 \beta$-estradiol (E2) and/or $100 \mathrm{nM}$ progesterone (P4). After 48 h RU486 was added to appropriate cells. All cells were grown for $72 \mathrm{~h}$ beyond the point of reaching $100 \%$ confluence. Samples that were P4 primed had P4 added when the cells were $\sim 80 \%$ confluent, i.e., $\sim t=-24 \mathrm{~h}$. 
Table 1. Genes selected for PCR reaction with primer sequence

\begin{tabular}{llll}
\hline \hline Gene Symbol & \multicolumn{1}{c}{ RefSeq ID } & Forward Primer & Reverse Primer \\
\hline ESR1 & NM_001122742 & AGGTGCCCTACTACCTGGAG & CTTCGTAGCATTTGCGGAGC \\
SMTN & NM_134270 & CTGTCTGGCCCCAAAGAGAC & TTGTTCACTCGGGTCTGCTC \\
CNN1 & NM_001299 & CAGAGAAGCAGGAGCGGAAA & CTGGTACTCGGGAGTCAGA \\
OXTR & NM_000916 & CAAGCTCATCTCCAAGGCCA & GGCTCAGGACAAAGGAGGAC \\
DHRS7C & NM_001105571 & GCTGATGCTCCCCCTGCTGC & CCCCAGCCTTGCCCCACCTG \\
LEPROT & NM_017526 & GAGATGGCGTGGAAAATCAG & TAGCCCCACGGCAGCACAAACC \\
C10orf99 & GTTCTCCGCTGTCTGGAGTC & CTCACCGTCTTCCTCATGGT \\
SCN4A & NM_007373 & AGGTTGTTCATCTCGCCATC & CTGCGATTACTGGTTCAGGA \\
NDUFA10 & GTACCCAGGGCTGTACTTGC & TATGAAGCGTTTGTGAGGCA \\
MYL6 & AF453834 & ATTCACACAGGGAAAGGCAC & GACGGTACTTCTGGGCCTCT \\
SRD5A2 & NM_079425 & ATTTCCAGTGCAGAAGGCAG & CACAGCTCACAGACACAGGAA \\
PLCD4 & NM_000348 & TCAGTGGTCAGCTGGTCTTG & GAAGGTGAAGGTCGGAGTCA \\
GAPDH & NM_032726 & TTGAGGTCAATGAAGGGGTC & \\
\hline
\end{tabular}

the median raw values only were inputted into GeneSpring. All data normalization and analyses were carried out in GeneSpring GX12.0 (Agilent Technologies). Data was log transformed and normalized by the percentile shift method using the 75 th percentile. Subsequently all normalized data was baseline-transformed to the median of all samples. Intensity values for all entities $(35,357)$ were initially filtered to exclude values that were $<50$ in at least two of six conditions (CON, E2, P4, P4/E2, P4/E2 + RU486, or P4 + RU486). Significantly differentially expressed genes were identified based on log values by a moderated $t$-test (68), with a $P$-value cut-off of 0.05 and a foldchange minimum of 1.5 -fold. No multiple-testing correction was applied. All data have been submitted to the Gene Expression Omnibus (GSE59231).

Gene ontology and transcriptional analysis of genes. A web-based system for the detection of overrepresented conserved transcription factor binding sites, oPOSSUM, was used to analyze sequences of specific, apparent coregulated, gene sets (33). Initially the genes differentially expressed on addition of individual hormones, P4 or E2, were analyzed. Transcription factor binding sites were considered significant if either the Z-score was $>10$ or the Fisher score was $>5$. Gene ontology (GO) analysis was performed using DAVID (Database for Annotation, Visualization and Integrated Discovery, v6.7) (21). Some gene annotation was not recognized by DAVID, and some genes had no GO annotation. Individual analyses were carried out on upregulated, downregulated and pooled regulated genes. The biological process GO category was given most weight though cell component and molecular function categories were noted where relevant, and other pathway and term analysis approaches using Panther, KEGG, and PIR keywords (all within DAVID) were also included.

Statistical analysis. All qPCR experiments were carried out in triplicate. Results are expressed as means \pm SD. $P$ values were used as a measure of the magnitude of the change and intersubject variability among the treated and control samples. $P$ values were calculated by Student's $t$-test using the GraphPad program (http:// www.graphpad.com/quickcalcs/ttest2.cfm, also see http://www. physics.csbsju.edu/stats/t-test_bulk_form.html).

\section{RESULTS}

Transcriptomic analysis of hUtSMCs after hormone treatment. Cells were 1) untreated or treated with 2) E2 alone, 3) $\mathrm{P} 4$ alone, 4) P4 and E2 in combination (P4/E2), 5) RU486 after P4/E2 incubation (P4/E2 + RU486), and 6) RU486 after $\mathrm{P} 4$ incubation (P4 + RU486). Cells in samples 4 and 5 were primed with P4 (see Fig. 1). Unlike other model organisms (both primate and nonprimate), the human myometrium is exposed to high concentrations of both estrogen and P4 during pregnancy (3). To mimic this steroid hormone environment, cultured hUtSMCs were exposed to both $10 \mathrm{nM}$ E2 and 100
nM P4 (concentrations correlating to circulating levels in mid to late pregnancy). P4 additions were made $24 \mathrm{~h}$ prior to E2 additions to mimic the earlier elevation of circulating P4 levels in pregnancy. A total of 18 slides were analyzed representing all conditions $(\mathrm{CON}, \mathrm{E} 2, \mathrm{P} 4, \mathrm{P} 4 / \mathrm{E} 2, \mathrm{P} 4 / \mathrm{E} 2+$ RU486 and P4 + RU486), with each condition analyzed in three independent experiments.

A total of 796 genes $(P<0.05$, fold change $>1.5$-fold $)$ showed significant differential expression following P4/E2 cotreatment of which 364 genes were upregulated and 432 downregulated (Supplemental Table S1). ${ }^{1}$ Fifty-three genes showed fold changes exceeding fivefold following P4/E2 treatment, of which the top 20 are shown (Table 2). Although 796 genes were significantly modulated transcriptionally by the combination of P4/E2, only 28 and 23 of these genes also showed significantly altered transcriptional regulation by the individual hormones $\mathrm{E} 2$ and $\mathrm{P} 4$, respectively (Fig. 2). This suggests that the combined effect of the hormones was much

${ }^{1}$ The online version of this article contains supplemental material.

Table 2. Top 20 genes with highest fold changes of expression following P4/E2 treatment

\begin{tabular}{lrrll}
\hline \hline Gene Symbol & Fold Change & $P$ Value & RefSeq ID & \multicolumn{1}{c}{ Operon ID } \\
\hline ALDH6A1 & 40.01 & 3.50E-02 & NM_005589 & H200009618 \\
COL5A3 & 27.35 & $1.95 \mathrm{E}-02$ & NM_015719 & opHsV0400006290 \\
UGT1A9 & 18.82 & $2.46 \mathrm{E}-02$ & NM_021027 & H300001271 \\
RANBP3L & 16.05 & $1.58 \mathrm{E}-02$ & NP_659437 & H200020602 \\
NXF5 & 13.05 & 6.80E-03 & NM_033154 & opHsV0400005823 \\
DNAH8 & 10.24 & $2.62 \mathrm{E}-02$ & & opHsV0400001435 \\
MIS12 & 9.75 & $3.79 \mathrm{E}-02$ & NM_024039 & H300014781 \\
NCOA7 & 9.65 & $3.48 \mathrm{E}-02$ & & H300012462 \\
CUL1 & 9.59 & $2.98 \mathrm{E}-02$ & NM_003592 & H300017702 \\
RALGPS1 & 9.53 & $3.47 \mathrm{E}-02$ & & H300015887 \\
GAS8 & -64.89 & $7.74 \mathrm{E}-04$ & NM_001481 & H300015231 \\
TTPA & -19.34 & $9.65 \mathrm{E}-04$ & NM_000370 & H200005658 \\
SHISA6 & -18.75 & $1.94 \mathrm{E}-02$ & NP_997269 & opHsV0400006883 \\
TYBN & -17.28 & $7.47 \mathrm{E}-03$ & & opHsV0400000537 \\
ABCA13 & -14.09 & $2.66 \mathrm{E}-02$ & NM_152701 & H300009369 \\
EFNA5 & -13.92 & $1.38 \mathrm{E}-02$ & NM_001962 & opHsV0400002585 \\
LYG2 & -13.61 & $2.69 \mathrm{E}-02$ & NM_175735 & opHsV0400002540 \\
DMRTB1 & -11.51 & $2.31 \mathrm{E}-02$ & NM_033067 & H200012954 \\
HKDC1 & -9.83 & $2.10 \mathrm{E}-02$ & NM_025130 & H200009369 \\
NPY & -9.75 & 3.85E-02 & NM_000905 & opHsV0400000153
\end{tabular}

Negative fold-change values represent downregulation. P4, progesterone; E2, 17 $\beta$-estradiol. 


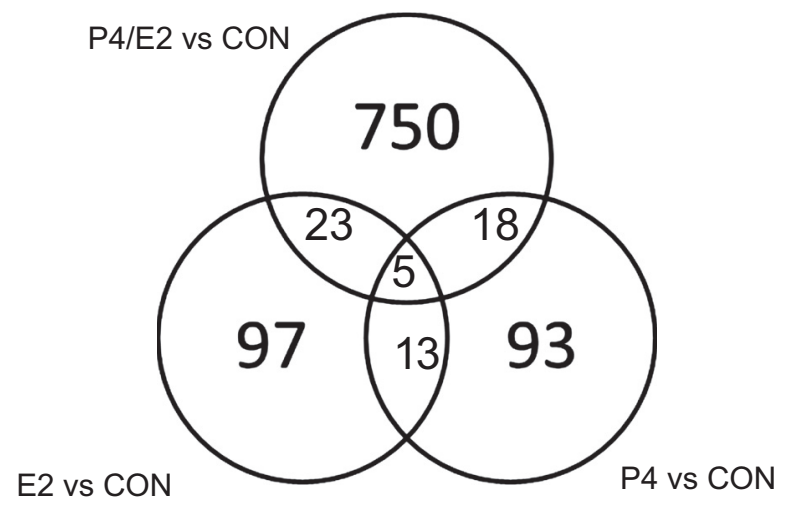

Fig. 2. Relationship of significant genes upon individual or combination additions of hormones. The number of genes (with annotation) significantly regulated $(P<0.05$, fold change $>1.5$-fold) under $\mathrm{P} 4 / \mathrm{E} 2$ conditions in relation to the number of genes significantly regulated by the individual P4 and E2 hormones.

greater than the sum of their individual effects. There were also genes whose expression suggested transcriptional modulation by the individual hormones (106 by P4, 110 by E2) and an absence of modulation by the combination of hormones (Fig. 2 ). This may indicate antagonistic effects of the individual hormones.

To identify genes that were differentially expressed in response to addition of the P4 antagonist RU486, we compared the expression profile of cells cotreated with P4/E2 with that of cells cotreated with P4/E2 to which RU486 was subsequently added (see Fig. 1). The expression of 666 fully annotated genes $(>1.5$-fold) was altered in cultured hUtSMCs treated with $\mathrm{P} 4 / \mathrm{E} 2+\mathrm{RU} 486$ compared with cells treated with P4/E2. The expression of 304 genes was upregulated and of 362 genes was downregulated in this experimental group (Supplemental Table S2). Seventy-two genes showed fold changes exceeding fivefold following P4/E2 + RU486 treatment, of which the top 20 are shown (Table 3).

The expression profiles of the significant P4/E2 differentially regulated genes (796 genes) showed modulated expression in some of the other conditions (E2, P4, P4 + RU486), but the vast majority showed reversal of transcriptional modulation in P4/E2 + RU486 conditions. Similarly the expression profiles of the significant P4/E2 \pm RU486 differentially regulated genes (666 genes) showed modulated expression in some of the other conditions, but the vast majority showed reversal of transcriptional modulation on addition of RU486. This suggested that virtually all P4/E2-regulated genes were also modulated by RU486, even though only $\sim 25 \%$ of genes were common to both sets. To show the similarity of the two sets, all P4/E2-modulated genes and all P4/E2 \pm RU486-modulated genes were separately clustered across all conditions investigated; both populations showed significant up- or downregulation upon $\mathrm{P} 4 / \mathrm{E} 2$ treatment and a return to near untreated levels following RU486 treatment. All regulated genes (here, for clarity, we only show the P4/E2 \pm RU486 group, not the two groups) were clustered into five expression profile sets across all conditions (Fig. 3).

The genes of the major cluster (cluster 1) showed no altered transcriptional regulation by $\mathrm{P} 4$, but considerable upregulation by the P4/E2 combination. RU486 restored expression levels to approximately those of the control. This cluster was mirrored by a second large cluster (cluster 2) that showed downregulated transcription by the P4/E2 combination. RU486 again reversed P4/E2 effects. A small cluster (cluster 3) was similar to cluster 2, but in addition these genes showed downregulated transcription following RU486 treatment of P4-treated cells. Cluster 4 genes were downregulated by E2 alone but upregulated by the P4/E2 combination. Cluster 5 showed the strongest downregulation of expression by the P4/E2 combination. Very few genes showed an expression profile different from the patterns shown in Fig. 3. Comparison of the expression profiles of P4/E2 + RU486-treated cells with cells treated with E2 alone indicated that there were very few genes whose expression was differentially modulated between these two conditions and was insufficient to identify any novel GO term (data not shown). This and additional comparisons (e.g., CON vs. P4 + RU486 and CON vs. P4/E2 + RU486) generated gene lists for which $\mathrm{GO}$ analysis extracted very few terms of significance. Therefore, there was no novel functional category outside that of its role as a P4 antagonist that could be ascribed to the effect of RU486.

Since gene expression is a measure of the combined actions of different transcription factors, it was of interest to investigate how the genes of each of the five expression profile clusters differed in their transcription factor binding site makeup. Using the 796 genes differentially regulated by P4/E2 as representative of the five clusters, oPOSSUM, a web-based system for the detection of overrepresented conserved transcription factor binding sites, was used to analyze sequences of the gene set (33). Initial interrogation of genes differentially expressed on addition of individual hormones, P4 or E2, identified a number of significant transcription factor binding sites. Two transcription factors from the hormone-nuclear receptor family (NR1H2::RXRA and NR3C1) were overrepresented on E2 treatment, and four from the Rel family (NFATC2, NF-кB, RELA, NFKB1) of transcription factors were overrepresented on P4 treatment (Table 4). Three of the five clusters of P4/E2-regulated genes (clusters 1, 2, and 3) showed significantly overrepresented binding sites for transcription factors. Of note, the putative transcription factors

Table 3. Top 20 genes with highest fold change in expression following RU486 addition to P4/E2 treated cells

\begin{tabular}{lccll}
\hline \hline Gene Symbol & Fold Change & $P$ Value & \multicolumn{1}{c}{ RefSeq ID } & \multicolumn{1}{c}{ Operon ID } \\
\hline TTPA & 30.83 & $2.14 \mathrm{E}-04$ & NM_000370 & H200005658 \\
DHRS7C & 23.28 & $9.86 \mathrm{E}-04$ & NM_001105571 & opHsV0400001964 \\
HMX3 & 15.00 & $5.69 \mathrm{E}-03$ & NM_001105574.1 & opHsV0400007372 \\
SV2B & 14.76 & $4.03 \mathrm{E}-02$ & NM_014848 & opHsV0400006274 \\
OR5H2 & 14.13 & $3.46 \mathrm{E}-02$ & NM_001005482 & H300007776 \\
NPY & 13.20 & $4.37 \mathrm{E}-02$ & NM_000905 & opHsV0400000153 \\
FAM78A & 12.94 & $5.68 \mathrm{E}-03$ & NM_033387 & opHsV0400000177 \\
SHISA6 & 12.83 & $4.66 \mathrm{E}-02$ & NM_207386 & opHsV0400006883 \\
LEPR/LEPROT & 12.64 & $1.01 \mathrm{E}-03$ & NM_001198683 & opHsV0400003795 \\
CPO & 12.58 & $1.21 \mathrm{E}-02$ & NM_173077 & H300003209 \\
PLEKHA2 & -20.39 & $2.71 \mathrm{E}-02$ & XM_496973 & H300012792 \\
TXNRD2 & -15.28 & $1.85 \mathrm{E}-02$ & NG_011835 & opHsV0400005683 \\
OSBPL1A & -15.16 & $1.83 \mathrm{E}-02$ & NG_029432 & opHsV0400002980 \\
HIST1H4A & -13.30 & $3.51 \mathrm{E}-02$ & NM_003538 & H300001107 \\
FCHO2 & -13.17 & $1.77 \mathrm{E}-02$ & XM_291142 & H300022280 \\
EMR3 & -13.11 & $3.09 \mathrm{E}-02$ & NM_032571 & opHsV0400005026 \\
C15orf27 & -12.14 & $3.02 \mathrm{E}-02$ & NM_152335 & H200021222 \\
TBC1D7 & -10.90 & 3.55E-03 & NM_001143964 & H300011765 \\
NDUFA10 & -10.90 & $2.26 \mathrm{E}-02$ & & H300016572 \\
RPL27 & -10.29 & $2.14 \mathrm{E}-04$ & NM_000988 & opHsV0400000214 \\
\hline
\end{tabular}

Negative fold-change values represent downregulation. 

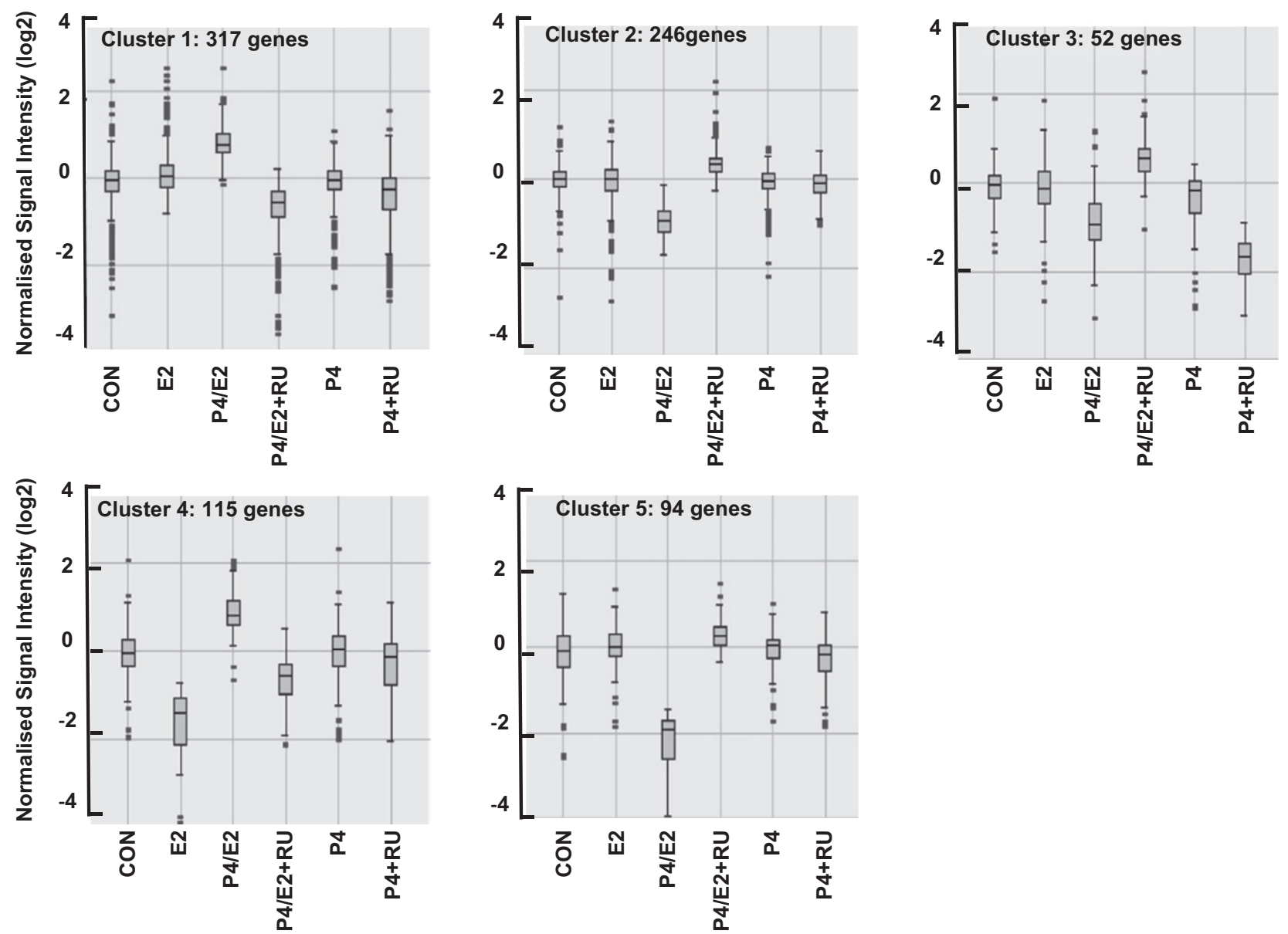

Fig. 3. Expression profile clustering of genes significantly differentially expressed on treatment of hUtSMCs with P4/E2. Genes significantly regulated $(P<0.05$, fold change $>1.5$ ) on addition of RU486 to hUtSMCs in P4/E2 conditions were clustered into 5 groups across all conditions (k-means clustering by Euclidean distance). The clusters are best displayed as box plots where the boxes (shaded) represent the $95 \%$ limits of the $\log 2$ normalized (and baseline centered) signal intensities and spots indicate outliers. (The total number here exceeds 666 genes because partially annotated genes were included).

associated with clusters 1 and 3 genes showed a high degree of overlap, including forkhead (FOX) factors, NKx factors, ARID3A, PDX1, HOXA5, SRY, and PRRX2, yet the cluster 1 and cluster 3 gene expression profiles were almost opposites. Furthermore, forkhead factors, NKx factors, and ARID3A were also significantly overrepresented in the E2-treated samples.

Quantitative and semiquantitative RT-PCR. Microarray analysis was validated by quantitative or semiquantitative RT-PCR on selected genes (Fig. 4). In samples cotreated with P4 and E2, the downregulation of TTPA ( $>19$-fold in microarray and $>5$-fold in qPCR, $P<0.005$ ) was confirmed by qRT-PCR (Fig. 4A). The signals for both BCL2 probes on the array were too weak to escape data filtering, but qPCR revealed over fivefold upregulation $(P<0.005)$. In the experimental group where $\mathrm{P} 4$ was functionally withdrawn from the P4/ E2-cotreated system by the addition of RU486, real-time qRT-PCR and semiquantitative RT-PCR analyses confirmed differential gene expression of EMILIN2 (downregulated, 10-fold) and TTPA (highest upregulated gene identified, 31-fold) (Fig. 4B). In addition, semiquantitative RT-PCR was carried out on eight genes (four downregulated: NDUFA10, MYL6, SRD5A2, and PLCD4, and four upregulated: DHRS7C, LEPROT, C10orf99, and SCN4A) identi- fied as differentially expressed in P4/E2 + RU486-treated samples compared with P4/E2-treated hUtSMCs (Fig. 4C). Differential expression of all selected genes identified by microarray analysis was confirmed by RT-PCR (Fig. 4, C and $D)$.

GO analysis of differentially expressed genes. To understand the biological significance of the differentially expressed genes identified following addition of RU486 to P4/E2-treated hUtSMCs, we performed GO analysis using DAVID (21). Of the original significant 666 genes identified, GO analysis identified significant terms for 397 genes. The most enriched biological process cluster, which included mostly upregulated genes, related to signal transduction (Fig. 5). In addition, using the other two GO categories (cell component and molecular function), it was clear that channel activity, transcription, and translation were very significant but that most activity was associated with the plasma membrane of the cell. Other GO pathway and term analysis approaches using Panther, KEGG, and PIR keywords (all within DAVID) reflected the initial GO analysis, though additional informative terms such as androgen and estrogen metabolism and cell surface receptor-mediated signal transduction were also significant. The direction of regulation was clear for genes assigned to some GO terms: transcription, translation, and metabolism 
Table 4. Statistically overrepresented transcription factor binding sites in hUtSMCs of genes significantly regulated under different hormonal combinations

\begin{tabular}{|c|c|c|c|c|c|}
\hline $\mathrm{TF}$ & Family & Target Gene Hits & Z Score & \multicolumn{2}{|c|}{ Fisher Score $/ P$ Value } \\
\hline \multicolumn{6}{|c|}{ E2 alone } \\
\hline Gata1 & GATA & 65 & 11.8 & 5.2 & 5.7E-03 \\
\hline Nkx2-5 & Homeo & 72 & 11.5 & 4.0 & $1.8 \mathrm{E}-02$ \\
\hline NFATC2 & Rel & 66 & 10.8 & 4.1 & 1.7E-02 \\
\hline ARID3A & Arid & 67 & 10.6 & 3.0 & 5.1E-02 \\
\hline NR1H2::RXRA & Hormone-nuclear Receptor & 2 & 10.1 & 2.9 & 5.3E-02 \\
\hline \multicolumn{6}{|c|}{ P4 alone } \\
\hline SP1 & BetaBetaAlpha-zinc finger & 49 & 14.7 & 0.6 & $5.5 \mathrm{E}-01$ \\
\hline NF-kappaB & Rel & 42 & 14.0 & 3.2 & 4.0E-02 \\
\hline $\mathrm{Pax} 4$ & Homeo & 2 & 11.9 & 2.6 & 7.5E-02 \\
\hline RELA & Rel & 41 & 10.5 & 5.4 & $4.5 \mathrm{E}-03$ \\
\hline NFKB1 & Rel & 22 & 10.3 & 2.9 & $5.8 \mathrm{E}-02$ \\
\hline NR3C1 & Hormone-nuclear Receptor & 17 & 10.0 & 3.9 & $2.1 \mathrm{E}-02$ \\
\hline \multicolumn{6}{|c|}{$\begin{array}{c}\text { P4/E2 } \\
\text { Cluster } 1, n=310\end{array}$} \\
\hline Nkx2-5 & Homeo & 202 & 31.6 & 14.2 & 7.0E-07 \\
\hline Foxd3 & Forkhead & 143 & 30.4 & 9.7 & $6.3 \mathrm{E}-05$ \\
\hline ARID3A & Arid & 193 & 27.1 & 13.1 & $2.0 \mathrm{E}-06$ \\
\hline Pdx1 & Homeo & 191 & 25.7 & 15.3 & 2.2E-07 \\
\hline HOXA5 & Homeo & 198 & 25.1 & 7.8 & 4.1E-04 \\
\hline SRY & High Mobility Group & 172 & 23.3 & 8.0 & 3.3E-04 \\
\hline FOXI1 & Forkhead & 145 & 22.7 & 9.1 & $1.2 \mathrm{E}-04$ \\
\hline Nobox & Homeo & 171 & 21.8 & 13.6 & $1.2 \mathrm{E}-06$ \\
\hline NKX3-1 & Homeo & 152 & 20.1 & 7.8 & 4.0E-04 \\
\hline Prrx2 & Homeo & 183 & 19.6 & 12.5 & $3.8 \mathrm{E}-06$ \\
\hline \multicolumn{6}{|c|}{ Cluster 2, $n=207$} \\
\hline Pax4 & Homeo & 3 & 13.8 & 3.4 & $3.2 \mathrm{E}-02$ \\
\hline Tal1::Gata1 & Helix-Loop-Helix & 44 & 10.5 & 2.0 & $1.4 \mathrm{E}-01$ \\
\hline Klf4 & Beta Beta Alpha-zinc finger & 101 & 8.7 & 6.4 & $1.6 \mathrm{E}-03$ \\
\hline PPARG::RXRA & Hormone-nuclear Receptor & 52 & 7.8 & 5.7 & $3.5 \mathrm{E}-03$ \\
\hline \multicolumn{6}{|c|}{ Cluster $3, n=193$} \\
\hline FOXI1 & Forkhead & 73 & 20.7 & 3.1 & 4.6E-02 \\
\hline HOXA5 & Homeo & 107 & 20.4 & 4.6 & $1.0 \mathrm{E}-02$ \\
\hline SRY & High Mobility Group & 90 & 18.9 & 3.4 & $3.2 \mathrm{E}-02$ \\
\hline Nkx2-5 & Homeo & 98 & 18.7 & 2.1 & $1.2 \mathrm{E}-01$ \\
\hline ARID3A & Arid & 92 & 18.1 & 1.7 & $1.8 \mathrm{E}-01$ \\
\hline Pdx 1 & Homeo & 85 & 17.1 & 0.9 & 4.2E-01 \\
\hline NFATC2 & Rel & 91 & 16.4 & 2.9 & $5.5 \mathrm{E}-02$ \\
\hline Prrx2 & Homeo & 89 & 16.3 & 2.4 & $8.9 \mathrm{E}-02$ \\
\hline FOXO3 & Forkhead & 81 & 15.8 & 2.3 & $1.0 \mathrm{E}-01$ \\
\hline Sox 5 & High Mobility Group & 79 & 15.0 & 2.6 & 7.8E-02 \\
\hline \multicolumn{6}{|c|}{ Cluster $4, n=60$} \\
\hline FOXA1 & Forkhead & 36 & -4.0 & 8.3 & $2.6 \mathrm{E}-04$ \\
\hline HNF1A & Homeo & 14 & 5.6 & 7.2 & 7.3E-04 \\
\hline YY1 & Beta Beta Alpha-zinc finger & 40 & 0.5 & 6.2 & 2.1E-03 \\
\hline NFATC2 & Rel & 37 & -0.7 & 6.1 & $2.2 \mathrm{E}-03$ \\
\hline Nkx3-2 & Homeo & 37 & -1.6 & 5.7 & 3.3E-03 \\
\hline ARID3A & Arid & 38 & 2.0 & 5.7 & 3.3E-03 \\
\hline RORA_2 & Hormone-nuclear Receptor & 14 & 6.4 & 5.7 & $3.4 \mathrm{E}-03$ \\
\hline Foxd3 & Forkhead & 30 & 1.1 & 5.5 & $4.0 \mathrm{E}-03$ \\
\hline Lhx3 & Homeo & 19 & 5.5 & 5.5 & 4.1E-03 \\
\hline Prrx2 & Homeo & 36 & 2.9 & 5.3 & $5.1 \mathrm{E}-03$ \\
\hline
\end{tabular}

Motifs are considered significant if the $\mathrm{Z}$ score is $>10$ or the Fisher score is $>5$. Only the top 10 transcription factors (TF) are shown for clusters 1 and 3 . Cluster 4 is small (60 genes) and Z scores are poor. These are included on the basis of the Fisher scores only. hUtSMC, human uterine smooth muscle cell. Motifs are considered significant if the Z-score is $>10$ or the Fisher score is $>5$ (indicated in boldface).

terms included genes that were mainly downregulated, whereas cell communication, response to external stimulus, and immune response genes were generally upregulated. Transport (solutes and ions) processes were associated with both up- and downregulated genes.

Similarly, GO analysis of the 796 genes differentially expressed in hUtSMCs treated with P4/E2 identified GO terms for 535 genes (data not shown). The most significant biological process terms were cell communication, signal transduction, differentiation, apoptosis, transcription, sensory perception, and inflammatory response. Because P4/E2 + RU486 treatment returned genes up- or downregulated in P4/E2 conditions to near control levels the GO terms for both analyses (Fig. 5) were similar. 
Fig. 4. PCR validation of differentially expressed genes following treatments. A: hUtSMCs were treated with $100 \mathrm{nM}$ P4 +10 nM E2 and harvested after $72 \mathrm{~h}$. Total RNA was extracted from the samples and untreated control and analyzed by quantitative (q)RT-PCR. Fold changes are relative to untreated control cells. $B$ : qRT-PCR validation of elastin microfibril interface-located protein 2 (EMILIN2) and $\alpha$-tocopherol transfer P4, $10 \mathrm{nM}$ E2, and cotreated with $1 \mu \mathrm{M}$ changes are expression levels in the presence image from semiquantitative PCR validation of selected genes after P4/E2 + RU486 treatment. $D$ : densitometry analysis of intensity values of image $\mathrm{C}$. The fold differences in each group were calculated by normalizing the values to the housekeeping gene (GAPDH) and comparing with corresponding untreated sample. Each value corresponds to the average from 3 independent experiments plotted $( \pm$ SD). Statistically significant differences between the treated and control samples were determined by Student $t$-test $(* P<0.05 ; * * P<0.005)$. For semiquantitative PCR amplification cycles were controlled to avoid the plateau effect. protein (TTPA) after treatment with $100 \mathrm{nM}$ RU486 $24 \mathrm{~h}$ prior to harvest at $72 \mathrm{~h}$. Fold of RU486 relative to its absence. $C$ : gel
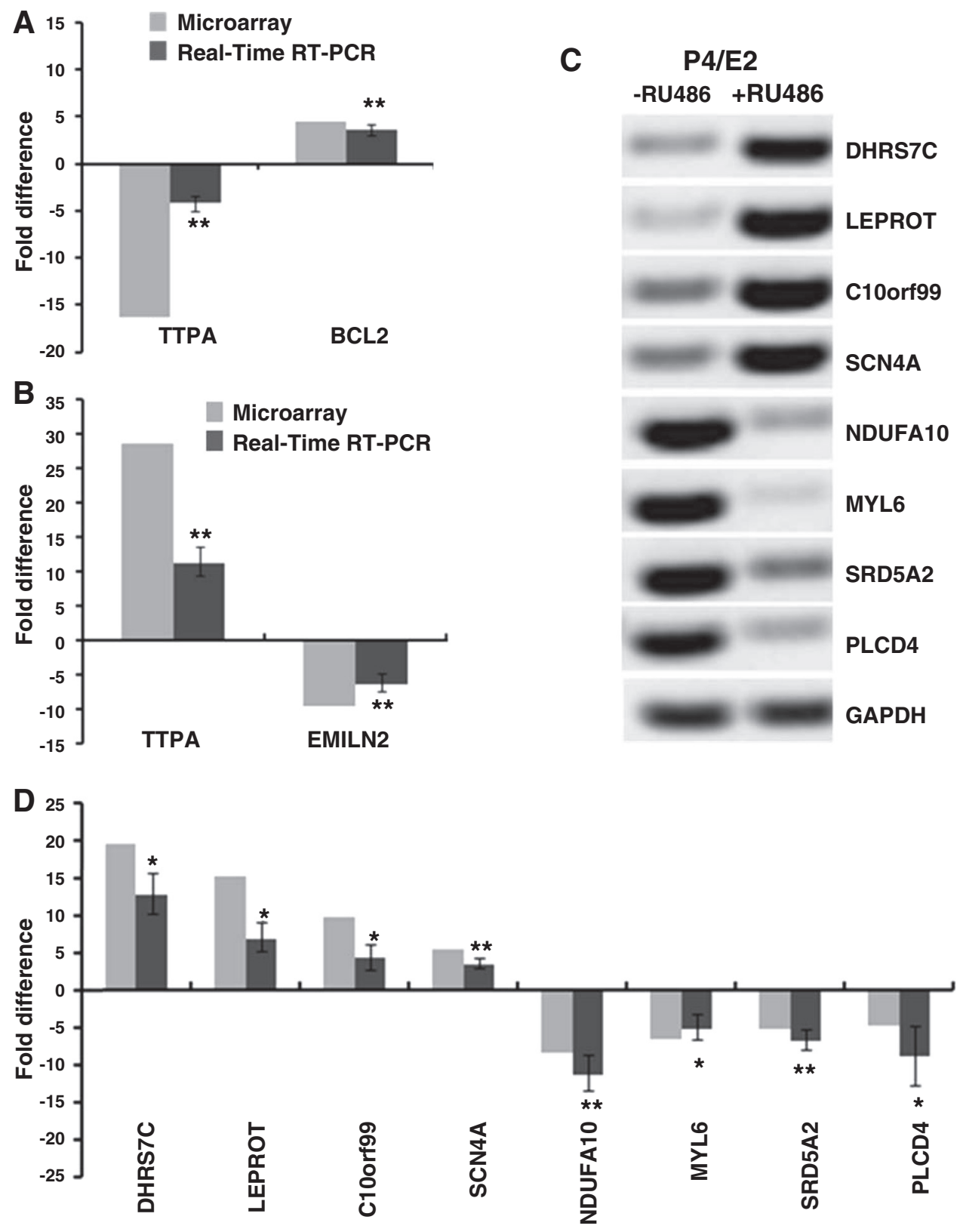

\section{DISCUSSION}

This study describes gene expression changes in response to $\mathrm{E} 2$ and $\mathrm{P} 4$, either alone or in combination, in an in vitro culture system of myometrial smooth muscle cells. In addition, it identifies transcriptional alterations elicited by the $\mathrm{P} 4$ antagonist RU486 on P4/E2-treated cells, when added to simulate functional withdrawal of P4 in the cell culture system, as occurs at the onset of human labor. A large number of genes were significantly transcriptionally modulated by E2 (110) or P4 (106) individually, but the most striking altered expression profiles were obtained under the combined P4/E2 treatment conditions (796 genes). The addition of RU486 to P4/E2treated cells led to altered expression transcriptional profiles for 666 genes. Our study revealed genes and pathways related to those identified in previous studies that analyzed the global transcriptomic profiles in pregnant and laboring myometrium in humans and other species $(32,53,62,69)$. The in vitro analysis of transcriptional alterations in hUtSMCs in response to two of the main steroid regulators provides important insights into the role played by a key individual cell type, the smooth muscle cell, in all physiological and pathophysiological states where these two hormones fluctuate. The main biological processes reported to be altered in the human myometrium during pregnancy and parturition (for which most data are available) are muscle contraction, ion channels and transporters, cell proliferation, immune and inflammatory responses, and coagulation (53).

The hUtSMC culture system used in these studies clearly does not replicate the complex interplay between different cell types in the uterus in vivo, during pregnancy and at labor. This in vitro model provides information on the specific and direct response of myometrial smooth muscle cells to different treat- 


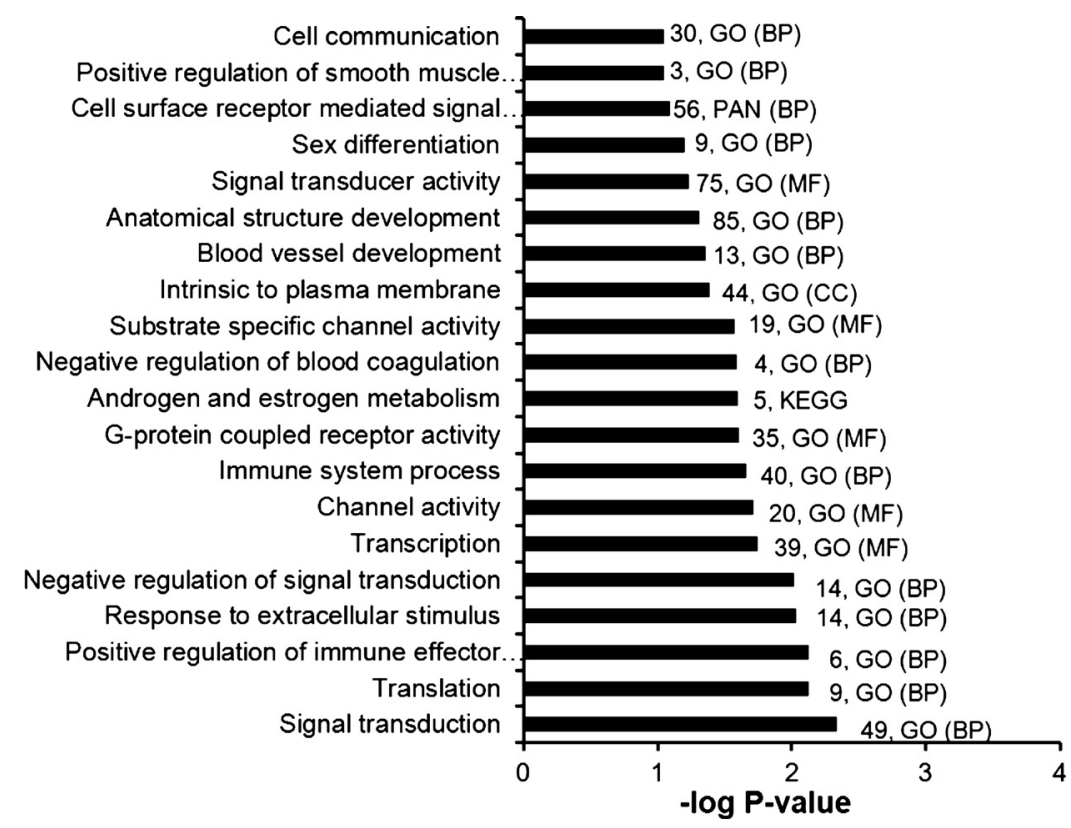

Fig. 5. Gene Ontology (GO) enrichment analysis. Enriched GO terms for differentially expressed genes identified following RU486 addition to P4/E2-treated hUtSMCs. All analyses were implemented within DAVID (21). The analysis focused GO biological process (BP) terms but included molecular function (MF), cellular component (CC), Panther (PAN) (http:// www.pantherdb.org/), and KEGG (http://www.genome.jp/ $\mathrm{kegg//}$ terms where these gave additional information. The prefix is the number of genes included in that term.

ments. As with similar in vitro models, this cell culture model system enables analysis of the effect of different treatments on specific cell types, in isolation; each type of study, in its own way, provides evidence of potential biological events occurring in vivo. These findings, therefore, provide the basis for future investigations in human myometrial tissue ex vivo and in vivo. The use of hUtSMCs to assess the effects of a broad range of natural biological compounds, including steroid hormones, and potential tocolytic agents on uterine smooth muscle cells has been reported in previous publications by ourselves and by others $(4,14,27,39)$. Confirmed expression of the oxytocin receptor (OXTR), calponin, and smoothelin genes (71) (data not shown) and immunofluorescence staining of smooth muscle $\alpha$-actin (55) attested to the smooth muscle origin of the cells.

Expression of both endogenous estrogen and progesterone receptors in myometrial smooth muscle cells is reported to decrease rapidly in culture (74). However, expression of estrogen receptor-alpha (ER- $\alpha$, now named ESR1) preferentially promotes the expression of P4 receptors (29). Microarray analysis confirmed the expression of ESR1 (ER- $\alpha)$, ESR2 (ER- $\beta$ ), PGR, and other related receptors (OXTR, ESRRA, ESRRB, mPRA, mPRB, mPRG, and PGRMC1) in hUtSMCs. qRT-PCR showed levels of the OXTR and ESR1 receptors at the approximate levels in pregnant nonlaboring myometrial cells (data not shown). Estrogen responsiveness of these cells had been shown previously (14), and P4 responsiveness was confirmed by the more than fivefold upregulation of BCL2 gene, a known P4-responsive gene $(48,72)$ (data not shown).

P4 is generally referred to as the hormone that promotes myometrial relaxation $(2,11)$. Its withdrawal at any stage of pregnancy initiates muscle contraction leading to labor (52). G protein-coupled receptor (GPCR) activation and reversible $\mathrm{Ca}^{2+}$-dependent phosphorylation of myosin light chain (MLC), catalyzed by myosin light chain kinase (MLCK), is a major determinant of smooth muscle contraction $(7,34)$. The regulation of contractility is described by $\mathrm{GO}$ terms such as $\mathrm{G}$ protein-coupled signaling, cell communication, channel activ- ity (voltage-gated cation channels), all of which were very significant in the analysis of the significantly modulated genes in P4/E2 and RU486-treated cells in this study. Most of the genes associated with the $\mathrm{G}$ protein-coupled signaling $\mathrm{GO}$ term were transcriptionally upregulated following the addition of RU486 to P4/E2-treated cells, and downregulated in the presence of P4/E2 compared with untreated cells. This is in agreement with the association of muscle relaxation (as modelled by $\mathrm{P} 4 / \mathrm{E} 2$ conditions) with a general desensitization of $\mathrm{G}$ protein-coupled signaling. The neuropeptide $\mathrm{FF}$ receptor 1 (GPR147) gene was upregulated 6.2-fold following the addition of RU486 and downregulated 8.0-fold by P4/E2 alone. GPR73L1, also known as prokineticin receptor 2, which is known to influence contraction-related effects in smooth muscle (63), was upregulated 5.3-fold in P4/E2-treated cells following the addition of RU486.

Another GPCR, the $\beta 2$-adrenergic receptor (AR) (Q13715_HUMAN) mRNA was downregulated (3.8-fold) following the addition of RU486 to P4/E2-treated cells. $\beta$-Adrenergic receptor $(\beta-\mathrm{AR})$ stimulates protein kinase $\mathrm{A}$ via cAMP, which opposes the contractile actions of PLC, phosphorylates MLCK and inhibits phosphorylation of MLC. Other studies have found that $\beta$-AR induction by progesterone plays an important role in uterine relaxation during pregnancy, and our in vitro transcriptomic results support this role (67). A previous study demonstrated GPCR transcriptional upregulation of the $\alpha 1-\mathrm{AR}$ and a number of other GPCRs in laboring rat myometrium (32). Other transcriptionally modulated players in the machinery of MLC phosphorylation were significantly downregulated following addition of RU486 to P4/E2-treated cells, including: NUAK1 (NUAK family of SNF1-like kinase 1) (3.8-fold) (73); ADRBK2 ( $\beta$-adrenergic receptor kinase 2 ) (58) (4.2-fold); and MYL6 (myosin light chain, smooth musclespecific) (30) (5.2-fold).

The PLC family of proteins, plays an important role in the activation of myometrial contractility and induction of labor (24, 64). Activation of any of the several forms of PLC stimulates $\mathrm{Ca}^{2+}$ release from internal stores and the activation 
of contraction-associated proteins $(6,45)$. The expression of phospholipase C, beta 1 (PLCB1), delta 4 (PLCD4), and gamma 2 (PLCG2) was all significantly downregulated in cultured hUtSMCs following addition of RU486 to P4/E2treated cells.

Contraction of myometrial smooth muscle cells is synchronized across the tissue by the concerted action of gap junctions and channels that contribute to efficient cell communication. In the presence of P4/E2, cell communication was the most significant gene ontology term relating to transcriptionally downregulated genes. Gap junction genes GJA8 [Connexin 50 (Cx50)] and GJA3 (Cx46) were significantly downregulated, 3.5 -fold and 1.7-fold, respectively, in hUtSMCs treated with P4/E2 and upregulated following the addition of RU486. In the lens tissue of the eye, $\mathrm{Cx} 50$ has been associated with calmodulin/ $\mathrm{Ca}^{2+}$ activity, phosphorylation of MLC, and interaction with aquaporin 0 (46). The results reported in this study correlate with previous studies in pregnant nonlaboring and laboring rat and mouse myometrium, reporting downregulation of gap junctions during pregnancy and their transcriptional activation at labor $(32,62)$. The expression of aquaporin 5 (AQP5), one of several related aquaporin channels that control water transport across cells, has been shown to be regulated by both estrogen and progesterone $(35,61)$. AQP5 was downregulated transcriptionally (2.9-fold) on addition of RU486 to P4/E2-treated hUtSMCs, in agreement with the results of a study by Helguera and colleagues (32) in pregnant laboring rat myometrium, where AQP5 mRNA was found to be upregulated during pregnancy and downregulated at labor.

$\mathrm{Ca}^{2+}$ ion movement and transport are essential components of the muscle contraction process. Equally essential is the range of ion transporters $\left(\mathrm{K}^{+}, \mathrm{Na}^{+}, \mathrm{Cl}^{-}\right)$that maintain an electrochemical gradient across the cell membrane and thereby regulate $\mathrm{Ca}^{2+}$ ion movement. Almost without exception, expression of genes associated with ion transport and cation channel activity was upregulated following the addition of RU486 to P4/E2-treated hUtSMCs. The potassium voltagegated channel (KCNQ2) was upregulated 8.5-fold following RU486 addition and was downregulated 7.4-fold in P4/E2treated cells, relative to untreated cells. The voltage-gated, type 4 sodium channel (SCN4A) showed similar large fold transcriptional changes, which were confirmed by qPCR. Other upregulated channels following addition of RU486 included $\mathrm{KCNJ} 10, \mathrm{KCNC} 2, \mathrm{SCN} 2 \mathrm{~B}$, and the voltage-dependent calcium channels CACNA1F and CACNA1C. Our results on ion channel expression are in agreement with previous studies comparing transcriptomes in pregnant and laboring mouse and rat myometrium, which also reported the upregulation of calcium ion channel transcription at labor $(32,62)$.

Activation of immune and inflammatory responses was observed following the addition of RU486 to P4/E2-treated cells; however, as expected in our in vitro model there was little evidence of the major in vivo reported effectors IL8, IL6, and CXCL6. One significantly upregulated (1.8-fold) gene was the regulator of calcineurin 2 (RCAN2), also known as calcipressin-2 (DSCR1L1). Expression of the RCAN family of proteins is induced by the NFAT transcription factors. Binding motifs for NFAT were most notably overrepresented in the P4/E2-regulated genes (Table 4), suggesting that NFAT factors are important regulators of gene expression in these hormonal conditions (59). IL1RN was downregulated 6.0-fold following addition of RU486, and since it antagonizes the proinflammatory interleukin 1 , its downregulation is essentially proinflammatory.

During the early stages of pregnancy, myometrial cells proliferate rapidly to accommodate the growing fetus (66) and reach a hypertrophic phase by midgestation (65). Late pregnancy in the rat myometrium is marked by an increase in apoptosis. In our system with P4/E2 treatment there was a balance of up- and downregulated apoptosis-related genes but on addition of RU486, proapoptotic genes were in general downregulated. EMILIN2 expression was significantly downregulated in P4/E2 + RU486-treated hUtSMCs compared with P4/E2-treated cells. EMILIN2 binds to TRAIL receptor DR4 to induce apoptosis (54). The role of ribosomal proteins in regulating cell proliferation and as inducers of cell death is well studied. In the present study, ribosomal protein RPL23 was downregulated (5.7-fold) in hUtSMCs treated with P4/E2 + RU486. RPL23 blocks the interaction between tumor suppressor gene p53 and MDM2, activating p53 and thereby inhibiting cell proliferation (75). These results correlate with those of a previous study in mouse myometrium, which also found that proapoptotic genes were downregulated at labor (62). BCL2 expression, an important determinant of cell proliferation, differentiation, and tumorigenesis, was upregulated 4.4-fold as determined by real-time qRT-PCR under the P4/E2 treatment conditions, as were two other BCL2 family members, BCL2A1 and BCL2L10, on the microarray (18). CUL1 (cullin 1), another key regulator of proliferation and apoptosis $(43,77)$, was strongly upregulated (9.6-fold) in P4/E2-treated cells. A core component of an E3 ubiquitin-protein ligase complex that targets specific proteins for degradation, CUL1 may also target cell cycle arrest proteins; therefore upregulation of CUL1 can clearly have a key regulatory role in determining proliferation or apoptosis. These results concur with transcriptional activation of genes associated with cell division, proliferation, and growth in rat myometrium, which were demonstrated to be upregulated during pregnancy and downregulated at labor (32).

A number of genes known to be involved in the hormonal regulation of uterine contractility during pregnancy and labor were identified as dysregulated as a result of the hormonal treatments of hUtSMCs. Steroid 5-alpha-reductase (SRD5A2) gene expression was downregulated ( $>5$-fold) in human myometrial smooth muscle cells treated with P4/E2 + RU486, compared with P4/E2-treated cells. Under the same conditions, aldo-keto reductase family 1, member D1 (AKR1D1), otherwise known as steroid 5-beta-reductase (SRD5B1), was upregulated $(>5$-fold). Both genes are important regulators of P4 metabolism and hence P4 levels $(15,42)$.

TTPA was upregulated ( $>30$-fold) following the addition of RU486 to P4/E2-treated cells. The importance of TTPA for the maintenance of pregnancy has been shown by the failure of TTPA knockout mice to reach term after implantation due to severe defects in placental development, which can be rescued with $\alpha$-tocopherol (vitamin E) supplementation (36). Gap junctions in myometrial strips can be protected from chemical damage by administration of $\alpha$-tocopherol (40).

In oPOSSUM analysis (Table 4) of P4/E2-regulated genes one common motif is that for NFAT. It was also overrepresented in the E2-regulated genes but not evident in the P4regulated genes. Five isoforms of NFAT are known; for four isoforms, signaling is mediated by the $\mathrm{Ca}^{2+} /$ calmodulin-de- 
pendent phosphatase calcineurin, and all are expressed in human myometrial cells (59). It has been shown that NFAT can respond to oxytocin pulses and regulate transcription by controlled translocation between the nucleus (on) and cytoplasm (off). NFAT could therefore be playing an important role in parturition by linking oxytocin and muscle contraction to NFAT transcriptional activation via $\mathrm{Ca}^{2+}$ levels and calcineurin (59). There is also an overrepresentation of forkhead transcription factor-binding sites in genes regulated by the P4/E2 combination treatment. Forkhead transcription factors have been associated with TA-rich ESR1 sites as opposed to GC-rich ESR2 sites (44). oPOSSUM analysis (Table 4) also identified genes regulated by the P4/E2 combination treatment with binding motifs for transcription factors NK-2/NK-3 (NKx2-5, NKx3-1, or NKx3-2), HOXA5, and ARID 3A. Nkx2-5 belongs to the NK-2 homeobox family and has been implicated in myocardial development, in both cardiomyocytes and smooth muscle (76). In an in vitro model of smooth muscle differentiation, the promoter of the smooth muscle gamma isoactin gene has been shown to bind NK-2 and serum response factor in intestinal smooth muscle cells (57). In uterine smooth muscle cells myocyte enhancer factor 2 is also bound in this complex (57). Previous studies have also reported the upregulation of several transcription factors associated with the transition from pregnant not-in-labor to laboring myometrium in rat, mouse and human $(8,16,25,28,32,53,62,69)$.

\section{Conclusions}

In the past decade, several functional genomic studies have been conducted to decipher the complex molecular mechanisms involved in pregnancy and parturition across species. The key events that regulate pregnancy and parturition are diverse and often species specific, making extrapolation from model species to the human condition difficult. Understanding the underlying mechanisms in humans is of utmost importance for the diagnosis and treatment of preterm and postterm labor. Establishing an in vitro myometrial cell culture model system to study human pregnancy and labor, therefore, has many associated benefits. In this study we have modelled the effects of two major steroid hormones to identify differentially expressed genes associated with the physiology of pregnancy, labor, estrus, and menopause, a model that also has possible implications for the pathophysiology of leiomyoma and endometrial cancer. Exposure of hUtSMCs to steroid hormonal conditions similar to those of the pregnant nonlaboring myometrium (P4/E2 treatment) altered the expression of genes favoring muscle cell relaxation, increased cell proliferation and growth, and reduced immune and inflammatory responses. These findings were similar to previously published results on in vivo myometrial samples (32). When P4 was functionally withdrawn from the P4/E2-cotreated cell culture system by the use of the P4 antagonist RU486, the altered expression of genes favored myometrial contraction, as seen by enrichment of biological processes such as muscle contraction, cell growth arrest and apoptosis, and immune and inflammatory response. While in vitro studies on isolated myometrial smooth muscle cells do not represent the full range of biological events occurring in vivo, they do allow the analysis of the specific effects of steroid hormones, individually and in combination, as well as the effects of functional P4 withdrawal on myome- trial cells. The findings in this study and other in vitro studies provide important insights into hormonal regulation of myometrial quiescence and contractility and form a basis for further research studies using freshly isolated myometrium ex vivo as well as in vivo studies using intact myometrium. This model could add to the debate about whether labor is an inflammatory response per se or an inflammatory response triggered by the fetus $(9,37)$. In the present cell culture model system the foreign body/fetus is absent, yet treatment of hUtSMCs with hormonal conditions of laboring myometrium triggered the alteration of gene expression that favored inflammatory responses. This would suggest that the inflammatory response elicited during parturition may be an effect of functional P4 withdrawal, though it should be noted that the major cytokine response was absent. Overall, it may be concluded that the hUtSMC culture system developed here behaved in accordance with reported in vivo myometrial responses. Thus this model cell culture system may be used for the functional study of various aspects of human myometrial physiology.

\section{DISCLOSURES}

No conflicts of interest, financial or otherwise, are declared by the author(s).

\section{AUTHOR CONTRIBUTIONS}

Author contributions: S.C. and M.O. performed experiments; S.C., M.T.C., M.O., E.O., and K.M. analyzed data; S.C., M.T.C., M.O., K.M., and T.J.S. interpreted results of experiments; S.C. drafted manuscript; M.T.C. prepared figures; M.T.C. and T.J.S. edited and revised manuscript; T.J.S. conception and design of research; T.J.S. approved final version of manuscript.

\section{REFERENCES}

1. Aguan K, Carvajal JA, Thompson LP, Weiner CP. Application of a functional genomics approach to identify differentially expressed genes in human myometrium during pregnancy and labour. Mol Hum Reprod 6: $1141-1145,2000$.

2. Albrecht ED. A role for estrogen in progesterone production during baboon pregnancy. Am J Obstet Gynecol 136: 569-574, 1980.

3. Albrecht ED, Aberdeen GW, Pepe GJ. The role of estrogen in the maintenance of primate pregnancy. Am J Obstet Gynecol 182: 432-438, 2000.

4. Attah AF, O'Brien M, Koehbach J, Sonibare MA, Moody JO, Smith TJ, Gruber CW. Uterine contractility of plants used to facilitate childbirth in Nigerian ethnomedicine. J Ethnopharmacol 143: 377-382, 2012.

5. Bailey J, Europe-Finner GN. Identification of human myometrial target genes of the c-Jun NH2-terminal kinase (JNK) pathway: the role of activating transcription factor 2 (ATF2) and a novel spliced isoform ATF2-small. $J$ Mol Endocrinol 34: 19-35, 2005.

6. Barany M. Biochemistry of Smooth Muscle Contraction. San Diego, CA: Academic, 1996.

7. Bernal AL. Overview of current research in parturition. Exp Physiol 86: 213-222, 2001.

8. Bethin KE, Nagai Y, Sladek R, Asada M, Sadovsky Y, Hudson TJ, Muglia LJ. Microarray analysis of uterine gene expression in mouse and human pregnancy. Mol Endocrinol 17: 1454-1469, 2003.

9. Bollapragada S, Youssef R, Jordan F, Greer I, Norman J, Nelson S. Term labor is associated with a core inflammatory response in human fetal membranes, myometrium, and cervix. Am J Obstet Gynecol 200: 104 e101-e111, 2009.

10. Breuiller-Fouche M, Charpigny G, Germain G. Functional genomics of the pregnant uterus: from expectations to reality, a compilation of studies in the myometrium. BMC Pregnancy Childbirth 7, Suppl 1: S4, 2007.

11. Brown AG, Leite RS, Strauss JF 3rd. Mechanisms underlying "functional" progesterone withdrawal at parturition. Ann NY Acad Sci 1034: 36-49, 2004.

12. Bukowski R, Hankins GD, Saade GR, Anderson GD, Thornton S. Labor-associated gene expression in the human uterine fundus, lower segment, and cervix. PLoS Med 3: e169, 2006. 
13. Chan EC, Fraser S, Yin S, Yeo G, Kwek K, Fairclough RJ, Smith R. Human myometrial genes are differentially expressed in labor: a suppression subtractive hybridization study. J Clin Endocrinol Metab 87: 2435 2441, 2002.

14. Chandran S, Cairns MT, O'Brien M, Smith TJ. Transcriptomic effects of estradiol treatment on cultured human uterine smooth muscle cells. Mol Cell Endocrinol 393: 16-23, 2014.

15. Charbonneau A, The VL. Genomic organization of a human 5 betareductase and its pseudogene and substrate selectivity of the expressed enzyme. Biochim Biophys Acta 1517: 228-235, 2001.

16. Charpigny G, Leroy MJ, Breuiller-Fouche M, Tanfin Z, MhaoutyKodja S, Robin P, Leiber D, Cohen-Tannoudji J, Cabrol D, Barberis C, Germain G. A functional genomic study to identify differential gene expression in the preterm and term human myometrium. Biol Reprod 68: 2289-2296, 2003.

17. Cordeaux Y, Tattersall M, Charnock-Jones DS, Smith GC. Effects of medroxyprogesterone acetate on gene expression in myometrial explants from pregnant women. J Clin Endocrinol Metab 95: E437-E447, 2010.

18. Craig RW. MCL1 provides a window on the role of the BCL2 family in cell proliferation, differentiation and tumorigenesis. Leukemia 16: $444-$ 454, 2002.

19. Cui W, Taub DD, Gardner K. qPrimerDepot: a primer database for quantitative real time PCR. Nucleic Acids Res 35: D805-D809, 2007.

20. Cuppoletti J, Malinowska DH, Chakrabarti J, Ueno R. Effects of lubiprostone on human uterine smooth muscle cells. Prostaglandins Other Lipid Mediat 86: 56-60, 2008.

21. Dennis G Jr, Sherman BT, Hosack DA, Yang J, Gao W, Lane HC, Lempicki RA. DAVID: Database for Annotation, Visualization, and Integrated Discovery. Genome Biol 4: P3, 2003.

22. Di WL, Lachelin GC, McGarrigle HH, Thomas NS, Becker DL. Oestriol and oestradiol increase cell to cell communication and connexin43 protein expression in human myometrium. Mol Hum Reprod 7: 671-679, 2001.

23. Dogan S, Deshpande DA, White TA, Walseth TF, Kannan MS. Regulation of CD 38 expression and function by steroid hormones in myometrium. Mol Cell Endocrinol 246: 101-106, 2006.

24. Dupuis M, Houdeau E, Mhaouty-Kodja S. Increased potency of alpha 1-adrenergic receptors to induce inositol phosphates production correlates with the upregulation of alpha $1 \mathrm{~d} / \mathrm{Gh}$ alpha/phospholipase $\mathrm{C}$ delta 1 signaling pathway in term rat myometrium. Reproduction 135: 55-62, 2008

25. Esnault S, Kelly EA, Johansson MW, Liu LY, Han ST, Akhtar M, Sandbo N, Mosher DF, Denlinger LC, Mathur SK, Malter JS, Jarjour NN. Semaphorin 7A is expressed on airway eosinophils and upregulated by IL-5 family cytokines. Clin Immunol 150: 90-100, 2014.

26. Esplin MS, Fausett MB, Peltier MR, Hamblin S, Silver RM, Branch DW, Adashi EY, Whiting D. The use of cDNA microarray to identify differentially expressed labor-associated genes within the human myometrium during labor. Am J Obstet Gynecol 193: 404-413, 2005.

27. Fitzgibbon J, Morrison JJ, Smith TJ, O'Brien M. Modulation of human uterine smooth muscle cell collagen contractility by thrombin, Y-27632, TNF alpha and indomethacin. Reprod Biol Endocrinol 7: 2, 2009.

28. Geimonen E, Boylston E, Royek A, Andersen J. Elevated connexin-43 expression in term human myometrium correlates with elevated c-Jun expression and is independent of myometrial estrogen receptors. J Clin Endocrinol Metab 83: 1177-1185, 1998.

29. Graham JD, Roman SD, McGowan E, Sutherland RL, Clarke CL. Preferential stimulation of human progesterone receptor B expression by estrogen in T-47D human breast cancer cells. J Biol Chem 270: 30693$30700,1995$.

30. Hailstones DL, Gunning PW. Characterization of human myosin light chains 1sa and 3nm: implications for isoform evolution and function. Mol Cell Biol 10: 1095-1104, 1990.

31. Havelock JC, Keller P, Muleba N, Mayhew BA, Casey BM, Rainey WE, Word RA. Human myometrial gene expression before and during parturition. Biol Reprod 72: 707-719, 2005.

32. Helguera G, Eghbali M, Sforza D, Minosyan TY, Toro L, Stefani E. Changes in global gene expression in rat myometrium in transition from late pregnancy to parturition. Physiol Genomics 36: 89-97, 2009.

33. Ho Sui SJ, Mortimer JR, Arenillas DJ, Brumm J, Walsh CJ, Kennedy BP, Wasserman WW. oPOSSUM: identification of over-represented transcription factor binding sites in co-expressed genes. Nucleic Acids Res 33: $3154-3164,2005$.
34. Ierardi JA, Paul DA, Ryan JP. Myosin light chain phosphorylation in contraction of gastric antral smooth muscle from neonate and adult rabbits. Pediatr Res 39: 156-159, 1996.

35. Jablonski EM, McConnell NA, Hughes FM, Huet-Hudson YM. Estrogen regulation of aquaporins in the mouse uterus: potential roles in uterine water movement. Biol Reprod 69: 1481-1487, 2003.

36. Jishage K, Arita M, Igarashi K, Iwata T, Watanabe M, Ogawa M, Ueda O, Kamada N, Inoue K, Arai H, Suzuki H. Alpha-tocopherol transfer protein is important for the normal development of placental labyrinthine trophoblasts in mice. J Biol Chem 276: 1669-1672, 2001.

37. Kelly RW. Inflammatory mediators and cervical ripening. $J$ Reprod Immunol 57: 217-224, 2002.

38. Khan-Dawood FS, Dawood MY. Estrogen and progesterone receptor and hormone levels in human myometrium and placenta in term pregnancy. Am J Obstet Gynecol 150: 501-505, 1984.

39. Koehbach J, O'Brien M, Muttenthaler M, Miazzo M, Akcan M, Elliott AG, Daly NL, Harvey PJ, Arrowsmith S, Gunasekera S, Smith TJ, Wray S, Goransson U, Dawson PE, Craik DJ, Freissmuth M, Gruber CW. Oxytocic plant cyclotides as templates for peptide G protein-coupled receptor ligand design. Proc Natl Acad Sci USA 110: 21183-21188, 2013.

40. Krieger TR, Loch-Caruso R. Antioxidants prevent gamma-hexachlorocyclohexane-induced inhibition of rat myometrial gap junctions and contractions. Biol Reprod 64: 537-547, 2001.

41. Lewis-Tuffin LJ, Jewell CM, Bienstock RJ, Collins JB, Cidlowski JA. Human glucocorticoid receptor beta binds RU-486 and is transcriptionally active. Mol Cell Biol 27: 2266-2282, 2007.

42. Lewis MJ, Wiebe JP, Heathcote JG. Expression of progesterone metabolizing enzyme genes (AKR1C1, AKR1C2, AKR1C3, SRD5A1, SRD5A2) is altered in human breast carcinoma. BMC Cancer 4: 27, 2004.

43. Lisztwan J, Marti A, Sutterlïty H, Gstaiger M, Wirbelauer C, Krek W. Association of human CUL-1 and ubiquitin-conjugating enzyme CDC34 with the F-box protein p45SKP2: evidence for evolutionary conservation in the subunit composition of the CDC34-SCF pathway. EMBO J 17: 368-383, 1998.

44. Liu Y, Gao H, Marstrand TT, Ström A, Valen E, Sandelin A, Gustafsson JÅ, Dahlman-Wright K. The genome landscape of ER $\alpha$ - and ERß-binding DNA regions. Proc Natl Acad Sci USA 105: 2604-2609, 2008.

45. Lodge S, Leach GD. The effects of phospholipase C on excitationcontraction coupling mechanisms in smooth muscle. J Pharm Pharmacol 25: 864-871, 1973.

46. Maddala R, Nagendran T, de Ridder GG, Schey KL, Rao PV. L-type calcium channels play a critical role in maintaining lens transparency by regulating phosphorylation of aquaporin-0 and myosin light chain and expression of connexins. PLoS One 8: e64676, 2013.

47. Makrigiannakis A, Margioris AN, Chatzaki E, Zoumakis E, Chrousos GP, Gravanis A. The decidualizing effect of progesterone may involve direct transcriptional activation of corticotrophin-releasing hormone from human endometrial stromal cells. Mol Hum Reprod 5: 789-796, 1999.

48. Matsuo H, Maruo T, Samoto T. Increased expression of Bcl-2 protein in human uterine leiomyoma and its up-regulation by progesterone. J Clin Endocrinol Metab 82: 293-299, 1997.

49. Mesiano S. Myometrial progesterone responsiveness. Semin Reprod Med 25: 5-13, 2007.

50. Mesiano S. Myometrial progesterone responsiveness and the control of human parturition. J Soc Gynecol Investig 11: 193-202, 2004.

51. Mesiano S. Roles of estrogen and progesterone in human parturition. Front Horm Res 27: 86-104, 2001

52. Mesiano S, Wang Y, Norwitz ER. Progesterone receptors in the human pregnancy uterus: do they hold the key to birth timing? Reprod Sci 18: 6-19, 2011.

53. Mittal P, Romero R, Tarca AL, Gonzalez J, Draghici S, Xu Y, Dong Z, Nhan-Chang CL, Chaiworapongsa T, Lye S, Kusanovic JP, Lipovich L, Mazaki-Tovi S, Hassan SS, Mesiano S, Kim CJ. Characterization of the myometrial transcriptome and biological pathways of spontaneous human labor at term. J Perinat Med 38: 617-643, 2010.

54. Mongiat M, Ligresti G, Marastoni S, Lorenzon E, Doliana R, Colombatti $\mathrm{A}$. Regulation of the extrinsic apoptotic pathway by the extracellular matrix glycoprotein EMILIN2. Mol Cell Biol 27: 7176-7187, 2007.

55. O'Brien M, Flynn D, Mullins B, Morrison JJ, Smith TJ. Expression of RHOGTPase regulators in human myometrium. Reprod Biol Endocrinol 6: 1,2008 
56. O'Brien M, Morrison JJ, Smith TJ. Upregulation of PSCDBP, TLR2, TWIST1, FLJ35382, EDNRB, and RGS12 gene expression in human myometrium at labor. Reprod Sci 15: 382-393, 2008.

57. Phiel CJ, Gabbeta V, Parsons LM, Rothblat D, Harvey RP, McHugh KM. Differential binding of an SRF/NK-2/MEF2 transcription factor complex in normal versus neoplastic smooth muscle tissues. J Biol Chem 276: 34637-34650, 2001.

58. Pitcher J, Lohse MJ, Codina J, Caron MG, Lefkowitz RJ. Desensitization of the isolated beta 2-adrenergic receptor by beta-adrenergic receptor kinase, cAMP-dependent protein kinase, and protein kinase C occurs via distinct molecular mechanisms. Biochemistry 31: 3193-3197, 1992.

59. Pont JNA, McArdle CA, Bernal AL. Oxytocin-stimulated NFAT transcriptional activation in human myometrial cells. Mol Endocrinol 26: 1743-1756, 2012.

60. Rehman KS, Yin S, Mayhew BA, Word RA, Rainey WE. Human myometrial adaptation to pregnancy: cDNA microarray gene expression profiling of myometrium from non-pregnant and pregnant women. Mol Hum Reprod 9: 681-700, 2003.

61. Richard C, Gao J, Brown N, Reese J. Aquaporin water channel genes are differentially expressed and regulated by ovarian steroids during the periimplantation period in the mouse. Endocrinology 144: 1533-1541, 2003.

62. Salomonis N, Cotte N, Zambon AC, Pollard KS, Vranizan K, Doniger SW, Dolganov G, Conklin BR. Identifying genetic networks underlying myometrial transition to labor. Genome Biol 6: R12, 2005.

63. Schweitz H, Pacaud P, Diochot S, Moinier D, Lazdunski M. MIT1, a black mamba toxin with a new and highly potent activity on intestinal contraction. FEBS Lett 461: 183-188, 1999.

64. Shojo H, Kaneko Y. Characterization and expression of oxytocin and the oxytocin receptor. Mol Genet Metab 71: 552-558, 2000

65. Shynlova O, Mitchell JA, Tsampalieros A, Langille BL, Lye SJ. Progesterone and gravidity differentially regulate expression of extracellular matrix components in the pregnant rat myometrium. Biol Reprod 70: 986-992, 2004.

66. Shynlova O, Oldenhof A, Dorogin A, Xu Q, Mu J, Nashman N, Lye SJ. Myometrial apoptosis: activation of the caspase cascade in the pregnant rat myometrium at midgestation. Biol Reprod 74: 839-849, 2006.

67. Simon V, Mhaouty-Kodja S, Legrand C, Cohen-Tannoudji J. Concomitant increase of $\mathrm{G}$ protein-coupled receptor kinase activity and un- coupling of beta-adrenergic receptors in rat myometrium at parturition. Endocrinology 142: 1899-1905, 2001.

68. Smyth GK. Linear models and empirical bayes methods for assessing differential expression in microarray experiments. Stat Appl Genet Mol Biol 3: 2004

69. Soloff MS, Jeng YJ, Izban MG, Sinha M, Luxon BA, Stamnes SJ, England SK. Effects of progesterone treatment on expression of genes involved in uterine quiescence. Reprod Sci 18: 781-797, 2011.

70. Tahara A, Tsukada J, Tomura Y, Wada K, Kusayama T, Ishii N, Yatsu T, Uchida W, Tanaka A. Pharmacologic characterization of the oxytocin receptor in human uterine smooth muscle cells. Br J Pharmacol 129: 131-139, 2000.

71. van Eys GJ, Niessen PM, Rensen SS. Smoothelin in vascular smooth muscle cells. Trends Cardiovasc Med 17: 26-30, 2007.

72. Yin P, Lin Z, Cheng YH, Marsh EE, Utsunomiya H, Ishikawa H, Xue Q, Reierstad S, Innes J, Thung S, Kim JJ, Xu E, Bulun SE. Progesterone receptor regulates $\mathrm{Bcl}-2$ gene expression through direct binding to its promoter region in uterine leiomyoma cells. J Clin Endocrinol Metab 92: 4459-4466, 2007.

73. Zagorska A, Deak M, Campbell DG, Banerjee S, Hirano M, Aizawa S, Prescott AR, Alessi DR. New roles for the LKB1-NUAK pathway in controlling myosin phosphatase complexes and cell adhesion. Sci Signal 3: ra25, 2010

74. Zaitseva M, Vollenhoven BJ, Rogers PA. In vitro culture significantly alters gene expression profiles and reduces differences between myometrial and fibroid smooth muscle cells. Mol Hum Reprod 12: 187-207, 2006.

75. Zhang Y, Shi Y, Li X, Du W, Luo G, Gou Y, Wang X, Guo X, Liu J, Ding J, Wu K, Fan D. Inhibition of the p53-MDM2 interaction by adenovirus delivery of ribosomal protein L23 stabilizes p53 and induces cell cycle arrest and apoptosis in gastric cancer. J Gene Med 12: 147-156, 2010.

76. Zhou B, von Gise A, Ma Q, Rivera-Feliciano J, Pu WT. Nkx2-5- and Isl1-expressing cardiac progenitors contribute to proepicardium. Biochem Biophys Res Commun 375: 450-453, 2008.

77. Zhou W, Wei W, Sun Y. Genetically engineered mouse models for functional studies of SKP1-CUL1-F-box-protein (SCF) E3 ubiquitin ligases. Cell Res 23: 599-619, 2013. 